\title{
An Analytical Approach to Harmonic Analysis and Controller Design of a STATCOM
}

\author{
Ben-Sheng Chen and Yuan-Yih Hsu, Senior Member, IEEE
}

\begin{abstract}
An analytical approach to harmonic analysis of a static synchronous compensator (STATCOM) based on Bessel functions of the first kind is described and a novel STATCOM controller with a fixed modulation index reference to minimize voltage and current harmonics is presented in this paper. Harmonic analysis of the STATCOM using the proposed analytical approach reveals that the total harmonic distortion of the STATCOM output voltage is minimal as the modulation index is fixed at unity at steady state. Then, a STATCOM controller with an adjustable modulation index during the transient period is designed by the pole assignment method to regulate ac system bus voltage in a very efficient manner. By comparing results obtained from the analytical approach, the computer simulations, and the experiments, it is concluded that the proposed analytical approach gives harmonic spectra which are very close to those from simulations and experiments. In addition, the step load change testings demonstrate the effectiveness of the proposed STATCOM controller in regulating ac bus voltage.
\end{abstract}

Index Terms-Harmonics, pole assignment, static synchronous compensator (STATCOM), voltage regulation, voltage-sourced inverter (VSI).

\section{INTRODUCTION}

$\mathbf{V}$ ARIOUS flexible ac transmission system (FACTS) devices, such as static synchronous compensators (STATCOMs), static synchronous series compensators (SSSCs), and unified power-flow controllers (UPFCs) are increasingly used in power systems because of their ability to stabilize power transmission systems and to improve power quality in power distribution systems. STATCOM technology is gradually employed to increase power transfer capability and provide voltage support [1], [2]. A \pm 160-MVA STATCOM was built and operated at Inez by AEP to provide voltage support and coordinate the control of area capacitor banks in 1997 [2]. And a 5-MVA, 4.16-kV distribution level STATCOM was installed to provide voltage flicker compensation, voltage stabilization, power factor control, and other functions for power-quality improvement in 1999 [3].

A lot of literature has been presented to analyze and design a variety of controllers for the STATCOM [4]-[11]. There are two control variables (phase angle $\alpha$ and modulation index $M I$ ) as a sinusoidal pulse-width modulation (SPWM) technique is applied to generate the inverter output voltage of the STATCOM. In [5], only the phase angle $\alpha$ was employed as the control

Manuscript received May 31, 2005; revised April 21, 2006. This work was supported by the National Science Council of the Republic of China under Contract NSC 94-2213-E-002-118. Paper no. TPWRD-00320-2005.

The authors are with the Department of Electrical Engineering, National Taiwan University, Taipei 106, Taiwan, R.O.C. (e-mail: d89921017@ntu. edu.tw; yyhsu@cc.ee.ntu.edu. tw).

Digital Object Identifier 10.1109/TPWRD.2006.883016 variable. The fast adjustment in inverter output voltage could not be achieved by this control scheme since the modulation index was held constant during the transient period. To achieve good dynamic response in inverter output voltage, a STATCOM control scheme with fixed $V d c^{*}$ and variable $M I$ has been proposed in [4]. Since the harmonic level changes with the variable modulation index, a steady-state modulation-index regulator is presented in this work to yield constant modulation index at the steady state such that the harmonics generated by the STATCOM are kept to a minimum. In addition, a transient modulation-index controller is proposed in order to achieve fast adjustment of the modulation index during the transient period such that the ac bus voltage can be regulated rapidly. An ac voltage controller and a current regulator are also designed in the proposed STATCOM controller.

To evaluate the harmonics generated by the STATCOMs with various control schemes, several works have been devoted to the analysis of these harmonics [12]-[14]. Usually, the STATCOM behavior was described by a set of differential equations and the conducting status of each switch element was modeled by a switching function [12]. Fourier analysis was applied to determine harmonic components of the STATCOM ac side current [13], [14]. In this work, an analytical approach is based on Bessel functions of the first kind to harmonic analysis of a PWM-based STATCOM with a saw-toothed trailing-edge carrier waveform. In contrast to previous works [15], [16], which gave the harmonic spectra for the voltages to dc capacitor neutral $N$, an approach is presented to analyze the harmonic spectra for the voltages to system neutral $n$.

The contents of this paper are as follows. First, an analytical approach to harmonic analysis of the STATCOM is described. Then, the architecture of the proposed STATCOM controller is presented and the design of the STATCOM output filter and dc capacitor is described. Finally, the voltage and current harmonic spectra obtained from computer simulations and experiments for the proposed STATCOM controller and the STATCOM controller with fixed $V d c^{*}$ and variable $M I$ at steady state are compared with those obtained by the analytical approach to the harmonic analysis of a STATCOM in order to demonstrate the effectiveness of the analytical approach. Simulation and experimental results for the steady-state operating condition and transient operating condition for the system subjected to step changes in load are presented in order to demonstrate the effectiveness of the proposed STATCOM controller.

\section{STATCOM OPERATING PRINCIPLE AT FUNDAMENTAL FREQUENCY}

As shown in Fig. 1, two impedance loads (one is fixed and the other is connected to the point of common coupling (PCC) 


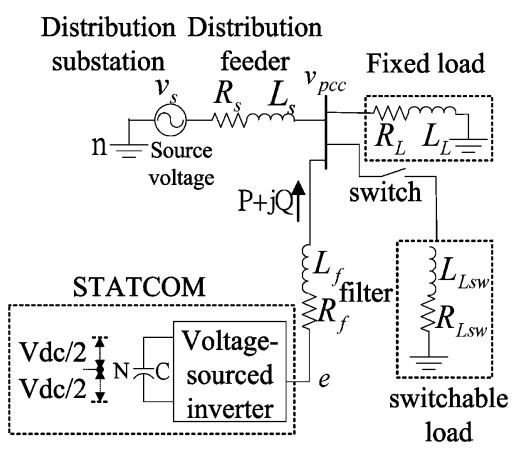

Fig. 1. Single-line diagram of a STATCOM connected to a power system.

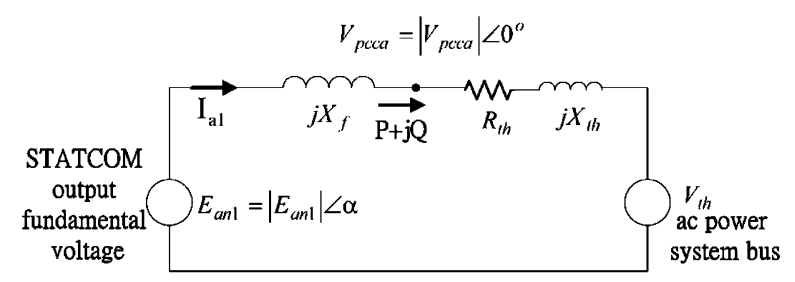

(a)

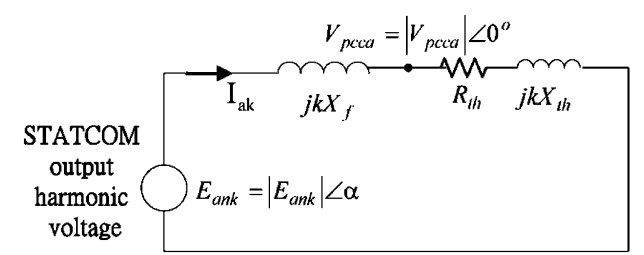

(b)

Fig. 2. Single-phase equivalent circuit of a STATCOM connected to a power system. (a) At fundamental frequency. (b) For harmonic analysis. ( $E_{a n 1}$ : the fundamental component of the STATCOM per phase output voltage $V_{p c c a}:$ PCC line-to neutral voltage $V_{t h}$ : Thevenin-equivalent line to neutral voltage of the power system $R_{t h}+j k X_{t h}$ : the Thevenin-equivalent impedance of the power system $\mathrm{I}_{\mathrm{a} 1}$ : the fundamental component of the phase-A ac current $\mathrm{I}_{\mathrm{ak}}$ : the $k$ th harmonic component of the phase-A ac current).

through a switch) are supplied power from a distribution substation with source voltage $v_{s}$ through a distribution feeder with the impedance $R_{s}+j \omega L_{s}$. To regulate the PCC bus voltage, a STATCOM, which is composed of a VSI and a dc capacitor, is included. The STATCOM is connected to the PCC through a coupling transformer and a filtering inductor which can be represented by the series impedance $R_{f}+j \omega L_{f}$.

\section{A. STATCOM Output Power}

Under balanced three-phase conditions, it is convenient to use the per-phase equivalent circuit as shown in Fig. 2(a) to explain how the STATCOM output reactive power can be modulated by a VSI using the pulse-width modulation (PWM) technique. For simplicity, the resistances of the coupling transformer and filtering inductor are neglected.

The complex power supplied by the STATCOM to the ac power system is given by the following equations [17]:

$$
\begin{aligned}
& P=\frac{\left|E_{a n 1}\right|\left|V_{\text {pcca }}\right|}{X_{f}} \sin \alpha \\
& Q=-\frac{\left|V_{\text {pcca }}\right|^{2}}{X_{f}}+\frac{\left|E_{a n 1}\right|\left|V_{p c c a}\right|}{X_{f}} \cos \alpha .
\end{aligned}
$$

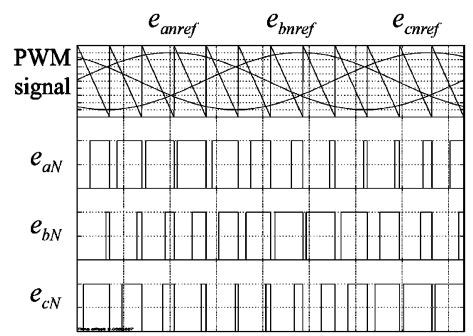

Fig. 3. PWM modulation process with a trailing-edge saw-toothed waveform and the STATCOM output voltage to the neutral $N$ of the dc capacitor.

To simplify the analysis, let $\left|V_{p c c a}\right|=1$. Then, we have

$$
\begin{aligned}
& P=\frac{\left|E_{a n 1}\right|}{X_{f}} \sin \alpha \\
& Q=-\frac{1}{X_{f}}+\frac{\left|E_{a n 1}\right|}{X_{f}} \cos \alpha .
\end{aligned}
$$

It is obvious from (3) and (4) that the STATCOM real power output $P$ and reactive power output $Q$ can be controlled by either its output voltage magnitude $\left|E_{a n 1}\right|$ or its phase angle $\alpha$ or both. In the design of a STATCOM controller, the reactive power output $Q$ is of major concern to us since the negative of $P$ simply gives us the real power that must be supplied by the ac bus to the STATCOM in order to cover the converter loss and transformer and filter loss (if any).

\section{B. Sensitivity Analysis}

To see whether the voltage magnitude $\left|E_{a n 1}\right|$ or phase angle $\alpha$ is more effective in controlling the STATCOM reactive power output, let us perform the sensitivity analysis [17]

$$
\begin{aligned}
\frac{\partial Q}{\partial\left|E_{a n 1}\right|} & =\frac{1}{X_{f}} \cos \alpha \\
\frac{\partial Q}{\partial \alpha} & =-\frac{\left|E_{a n 1}\right|}{X_{f}} \sin \alpha .
\end{aligned}
$$

In normal operation, $\left|E_{a n 1}\right|$ is close to unity and $|\alpha|$ is very small [4]. As a result, $\cos \alpha \approx 1, \sin \alpha \approx 0$, and $|\partial Q / \partial| E_{a n 1} \| \gg|\partial Q / \partial \alpha|$. In other words, the voltage magnitude $\left|E_{a n 1}\right|$ is more effective than the phase angle $\alpha$ in controlling the reactive power output $Q$. Thus, it is desirable to control the voltage magnitude $\left|E_{a n 1}\right|$ when we try to regulate PCC bus voltage under disturbance conditions.

\section{Proposed Analytical ApProach to the ANALYSIS OF LINE-TO-NEUTRAL FUNDAMENTAL VOLTAGE AND HARMONIC VOLTAGES}

For a three-phase system, one single-phase modulation, as shown in Fig. 3 [15], is adopted due to minimum harmonics. A single saw-toothed trailing-edge carrier is compared with three sinusoidal modulating reference signals with $120^{\circ}$ phase shift to generate the gate pulse trains for a three-phase two-level PWM inverter. The resulting STATCOM output voltages to the neutral $\mathrm{N}$ of the dc capacitor $e_{a N}, e_{b N}$, and $e_{c N}$ as shown in Fig. 3 can be expressed as follows [15], [16], as shown in (7)-(9) at 
the bottom of the page, where $\omega_{f}$ is the fundamental angular frequency of the ac power system $(\mathrm{rad} / \mathrm{s}), \omega_{c}$ is the angular frequency of the carrier signal ( $\mathrm{rad} / \mathrm{s}), M I$ is the modulation index, $\mathrm{Vdc}$ is the dc capacitor voltage, and $J_{0}$ and $J_{n}$ are the Bessel functions of the first kind.

In (7)-(9), the first term, which is proportional to the modulation index $M I$, gives the amplitudes for the fundamental voltage. The second term gives the amplitudes for the harmonics at carrier frequency $\omega_{c}$ and at the multiples of the carrier frequency $\left(m \omega_{c}\right)$. On the other hand, the third term gives the amplitudes for the harmonics at sidebands around multiples of the carrier frequency $\left(m \omega_{c}+n \omega_{f}\right)$.

Since we are concerned about the harmonic spectra of the phase-to-system neutral $(n)$ voltage $\left(e_{a n}, e_{b n}\right.$, and $\left.e_{c n}\right)$ instead of the voltage to the dc capacitor neutral $(N)\left(e_{a N}, e_{b N}\right.$, and $e_{c N}$ ), we first subtract (8) from (7) to obtain the line-to-line STATCOM output voltage

$$
\begin{aligned}
e_{a b}(M I, V d c, t)=e_{a N}( & M I, V d c, t)-e_{b N}(M I, V d c, t) \\
=V d c( & -\frac{\sqrt{3} M I}{2} \sin \left(\omega_{f} t-\frac{1}{3} \pi\right) \\
& -\sum_{m=1}^{m=\infty} \sum_{n= \pm 1}^{n= \pm \infty} \frac{2 J_{n}(m \pi M I)}{m \pi} \\
& \cdot \cos \left(m \omega_{c} t+n \omega_{f} t-m \pi-\frac{5 n \pi}{6}\right) \\
& \left.\cdot \sin \left(\frac{1}{3} n \pi\right)\right) .
\end{aligned}
$$

In (10), the harmonics at the carrier frequency and multiples of the carrier frequency are all eliminated. In fact, this is a major advantage of the single-phase modulation compared to other modulation techniques [15]. Then, the line-to-neutral STATCOM output voltage can be obtained as follows:

$$
E_{a n k}=\frac{1}{\sqrt{3}} e^{j \beta} E_{a b k}
$$

where $\beta=0, k=3 v, \beta=-\pi / 6, k=3 v+1, \beta=+\pi / 6$, $k=3 v+2$, and $v$ is any integer.

From (11), we have the fundamental voltage $e_{a n 1}$ and harmonic voltage $e_{\text {ank }}$

$$
\begin{aligned}
e_{a n 1}= & -\frac{M I \cdot V d c}{2} \sin \left(\omega_{f} t-\frac{\pi}{3}-\frac{\pi}{6}\right) \\
e_{a n k}= & -\frac{2 V d c \cdot J_{n}(m \pi M I)}{\sqrt{3} \cdot m \pi} \\
& \cdot \cos \left(m \omega_{c} t+n \omega_{f} t-m \pi-\frac{5 n \pi}{6}+\beta\right) \\
& \cdot \sin \left(\frac{n \pi}{3}\right)
\end{aligned}
$$

where $k=m \times p+n, \beta=0, k=3 v, \beta=-\pi / 6, k=3 v+1$, $\beta=+\pi / 6, k=3 v+2, p$ is the ratio of the carrier frequency to the modulation frequency, and $v$ is any integer. Then, the fundamental and harmonic output currents of the STATCOM can be obtained as follows:

$$
I_{a 1}=\frac{E_{a n 1}(M I, V d c)}{R_{t h}+j \omega L_{t h}}
$$

$$
\begin{aligned}
& e_{a N}(M I, V d c, t)=V d c\left(\frac{M I}{2} \cos \left(\omega_{f} t\right)\right. \\
& +\sum_{m=1}^{m=\infty} \frac{1}{m \pi}\left(\sin \left(m \omega_{c} t\right)-J_{0}(m \pi M I) \sin \left(m \omega_{c} t-m \pi\right)\right) \\
& \left.-\sum_{m=1}^{m=\infty} \sum_{n= \pm 1}^{n= \pm \infty} \frac{J_{n}(m \pi M I)}{m \pi} \sin \left(m \omega_{c} t+n \omega_{f} t-m \pi-\frac{n \pi}{2}\right)\right) \\
& e_{b N}(M I, V d c, t)=V d c\left(\frac{M I}{2} \cos \left(\omega_{f} t-\frac{2}{3} \pi\right)\right. \\
& +\sum_{m=1}^{m=\infty} \frac{1}{m \pi}\left(\sin \left(m \omega_{c} t\right)-J_{0}(m \pi M I) \sin \left(m \omega_{c} t-m \pi\right)\right) \\
& \left.-\sum_{m=1}^{m=\infty} \sum_{n= \pm 1}^{n= \pm \infty} \frac{J_{n}(m \pi M I)}{m \pi} \sin \left(m \omega_{c} t+n\left(\omega_{f} t-\frac{2}{3} \pi\right)-m \pi-\frac{n \pi}{2}\right)\right) \\
& e_{c N}(M I, V d c, t)=V d c\left(\frac{M I}{2} \cos \left(\omega_{f} t+\frac{2}{3} \pi\right)\right. \\
& +\sum_{m=1}^{m=\infty} \frac{1}{m \pi}\left(\sin \left(m \omega_{c} t\right)-J_{0}(m \pi M I) \sin \left(m \omega_{c} t-m \pi\right)\right) \\
& \left.-\sum_{m=1}^{m=\infty} \sum_{n= \pm 1}^{n= \pm \infty} \frac{J_{n}(m \pi M I)}{m \pi} \sin \left(m \omega_{c} t+n\left(\omega_{f} t+\frac{2}{3} \pi\right)-m \pi-\frac{n \pi}{2}\right)\right)
\end{aligned}
$$




$$
I_{a k}=\frac{E_{a n k}(M I, V d c)}{R_{t h}+j k \omega L_{t h}} .
$$

From (12) and (13), the rms value of the line-to-neutral fundamental and harmonic output voltages of the STATCOM can be obtained as follows:

$$
\begin{aligned}
& \left|E_{a n 1}\right|=\frac{M I \cdot V d c}{2 \sqrt{2}} \\
& \left|E_{a n k}\right|=\left|\sqrt{\frac{2}{3}} \cdot \frac{V d c J_{n}(m \pi M I)}{m \pi} \cdot \sin \left(\frac{n \pi}{3}\right)\right| .
\end{aligned}
$$

Then, the total harmonic distortion of the STATCOM output voltage can be defined as follows [18]:

$$
\mathrm{THDv}=\frac{\sqrt{\sum_{k=2}^{\infty}\left|E_{a n k}\right|^{2}}}{\left|E_{a n 1}\right|} .
$$

And the THD of the STATCOM output current can be defined as follows [18]:

$$
\text { THDi }=\frac{\sqrt{\sum_{k=2}^{\infty}\left|\frac{E_{a n k}}{j k X_{t h}}\right|^{2}}}{\left|\frac{\left(E_{a n 1}-V_{t h}\right)}{j X_{t h}}\right|}=\frac{\sqrt{\sum_{k=2}^{\infty}\left|\frac{E_{a n k}}{k}\right|^{2}}}{\left|E_{a n 1}-V_{t h}\right|} .
$$

The THD of the STATCOM output voltage generated by switching frequency and its harmonics in (18) versus the modulation index $M I$ is plotted in Fig. 4. It is obvious that a higher modulation index will give a lower THD. It is also noted that the lowest THD in the linear modulation region is achieved when $M I=1$.

\section{Proposed Statcom Controller}

As shown in Fig. 5, the STATCOM is controlled to deliver either inductive or capacitive currents to the power system by varying its output voltages $e_{a}, e_{b}$, and $e_{c}$. In the design of the STATCOM controller, the three-phase quantities $v_{a}, v_{b}, v_{c}, e_{a}$, $e_{b}, e_{c}, i_{a}, i_{b}$, and $i_{c}$ are first transformed to the quantities $v_{d}, v_{q}$, $e_{d}, e_{q}, i_{d}$, and $i_{q}$ in the synchronously rotating reference frame [4]. Then, a current regulator is employed to reach decoupled current control [4]. In addition, an ac voltage controller is designed to regulate the PCC bus voltage through a proportionalintegral (PI) controller. The ac voltage controller generates the desired reactive current reference $i_{q}^{*}$ for the current regulator.

In the design of the STATCOM controller, it is essential to have good dynamic response in the transient period and to ensure minimal harmonics at steady state. As shown in Fig. 5, a transient modulation-index controller and a steady-state modulation-index regulator are proposed to achieve the goals of good transient response and minimal steady-state harmonics, respectively. Details on the design of the transient modulation-index controller and the steady-state modulation-index regulator are described below.

\section{A. Transient Modulation-Index Controller}

It has been observed in (5) that an efficient way to modulate the reactive power output $Q$ of the STATCOM and to regulate the PCC bus voltage is to control the voltage magnitude $\left|E_{a n 1}\right|$

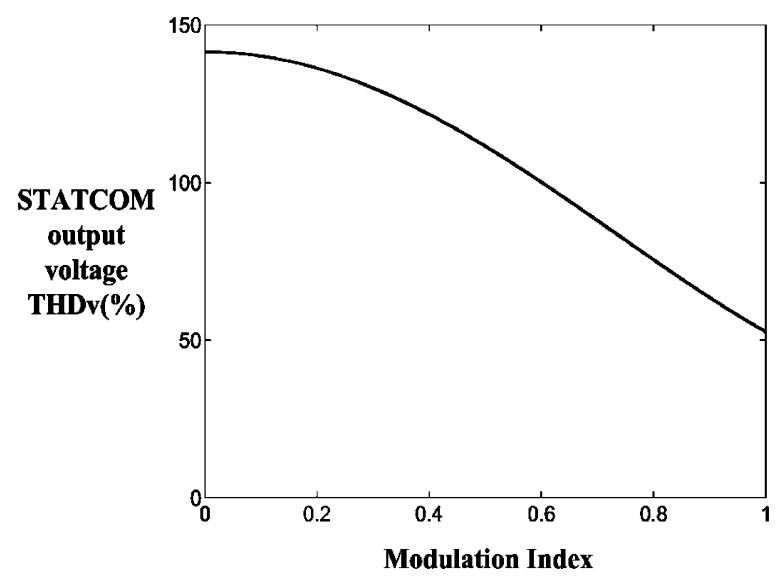

Fig. 4. Total harmonic distortion of the STATCOM output voltage.

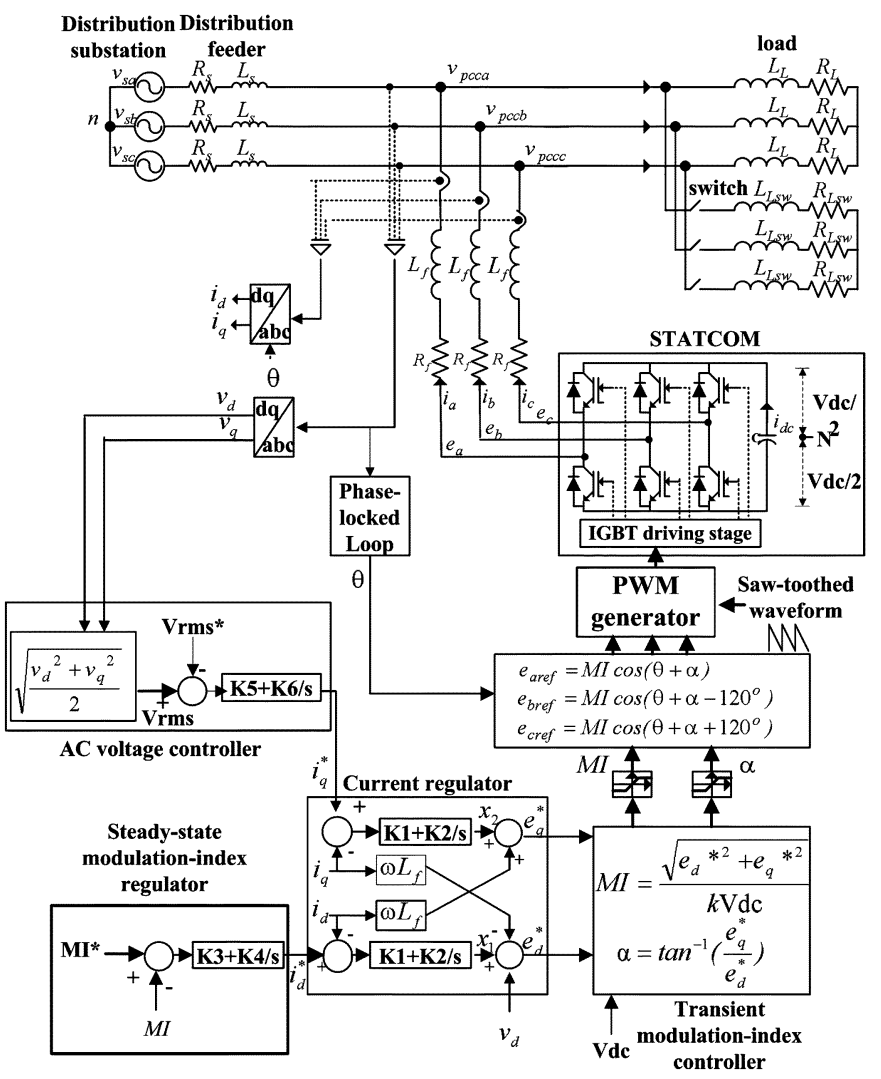

Fig. 5. Proposed STATCOM controller.

in the transient period. As noted in (16), the fundamental voltage $\left|E_{a n 1}\right|$ of the STATCOM output is proportional to the product of MI and Vdc. Since it is impossible to change Vdc instantaneously, it is desirable to adjust the modulation index $M I$ in the transient period such that the PCC bus voltage can be regulated efficiently through the fast modulation of $M I,\left|E_{a n 1}\right|$, and $Q$. Thus, a transient modulation-index controller as shown in Fig. 5 is proposed to adjust the modulation index $M I$ rapidly in the transient period.

\section{B. Steady-State Modulation-Index Regulator}

It has also been observed in Fig. 4 that a lower modulation index would give higher harmonic contents at steady state. Thus, 
TABLE I

SYSTEM PARAMETERS USED IN SIMULATIONS AND EXPERIMENTS

\begin{tabular}{|l|c|}
\hline Fundamental frequency & $f=60 \mathrm{~Hz}$ \\
\hline Source voltage & $v_{s}=78 \mathrm{~V}_{\text {peak }}\left(110 \mathrm{VL} L_{r m s}\right)$ \\
\hline Source resistance & $R_{s}=0.7 \Omega$ \\
\hline Source inductance & $L_{s}=1.6 \mathrm{mH}$ \\
\hline Filter inductance & $L_{f}=0.01 \mathrm{H}$ \\
\hline Filter resistance & $R_{f}=0.4$ \\
\hline Switching frequency & $f_{c}=1920 \mathrm{hz}$ \\
\hline DC capacitor capacitance & $C=2200 \mathrm{uF}$ \\
\hline Estimated inverter loss & $R p=5000 \Omega$ \\
\hline Reactance of fixed RL load & $L_{L}=40 \mathrm{mH}$ \\
\hline Resistance of fixed RL load & $R_{L}=8.4 \Omega$ \\
\hline Reactance of switched RL & $L_{L S w}=35.5 \mathrm{mH}$ \\
\hline Resistance of switched RL & $R_{L s w}=7 \Omega$ \\
\hline Sampling frequency & $f_{s}=15360 \mathrm{~Hz}$ \\
\hline
\end{tabular}

it is desirable to have the modulation index $M I$ fixed at unity at steady state in order to ensure minimal harmonics at steady state. To achieve this goal, a steady-state modulation-index regulator is proposed in Fig. 5 to drive the modulation index to the preset value $\left(M I^{*}=1\right.$ in this work) at steady state through the action of a PI controller. As shown in Fig. 5, the real current reference $i_{d}^{*}$ is generated by the proposed steady-state modulation-index regulator.

Using the proposed steady-state modulation-index regulator and transient modulation-index controller, the advantage of minimal harmonics can be retained under steady-state situations. When there is a need to adjust the reactive power output during the transient period, the actual modulation index $M I$ is no longer equal to the steady-state reference modulation index $M I^{*}$ which is equal to the preset value. As a result, the modulation index $M I$ deviates from the steady-state value $M I^{*}$. However, this deviation of the modulation index has little effect on steady-state harmonic contents since the transient lasts for only a very short period. With the adjustment of the modulation index by the proposed STATCOM controller during the transient period, the STATCOM output voltage $|E|$ and reactive power $Q$ can be modulated in a very rapid manner. It is expected that the proposed STATCOM controller responds faster than the conventional $\alpha$ STATCOM controller where the fixed modulation index limits the response speed [5].

\section{Design of the PI Controller}

In order to determine proper proportional-integral controller gains $K 1, K 2, K 3, K 4, K 5$, and $K 6$ for the current regulator, the steady-state modulation-index regulator, and the ac voltage controller, the main circuit, and the control system in Fig. 5 are first combined together in the standard state equation as follows:

$$
\dot{X}=f(x, d, t)
$$

where $x=\left[\begin{array}{lllllllll}i_{s d} & i_{s q} & i_{d} & i_{q} & v_{d c} & e_{d}^{*} & e_{q}^{*} & i_{d}^{*} & i_{q}^{*}\end{array}\right]^{T}$ is the state vector and $d=\mathrm{Vrms}^{*}$ is the ac bus voltage reference. The parameters for the system under study are listed in Table I.

In order to determine proper parameters for the current regulator, the steady-state modulation-index regulator, and the ac voltage controller, the pole assignment approach will be used.
TABLE II

SYSTEM EIGENVALUES AT FULL LOAD AND $i_{q}^{*}=-5 \mathrm{~A}$

\begin{tabular}{|l|c|}
\hline $\begin{array}{l}\text { System with } \\
\text { STATCOM } \\
\text { but without } \\
\text { controller }\end{array}$ & $\left.\begin{array}{c}\text { System with STATCOM and } \\
\text { with AC voltage controller } \\
K 1=15, K 2=15, K 3=10, \\
K 4=50, K 5=-1.23, \quad K 6=-60\end{array}\right)$ \\
\hline$-227 \pm j 377$ & $-216 \pm j 377$ \\
\hline$-85 \pm j 377$ & $-2070,-420$ \\
\hline-0.187 & -7.94 \\
\hline & $-9.06 \pm j 9.06$ \\
\hline & $-1,-1$ \\
\hline
\end{tabular}

To do this, the nonlinear equations of the study system as described in (20) are linearized around a nominal operating condition and the resulting linearized state equation is given by

$$
\begin{aligned}
& \dot{X}(t)=A X(t)+E d \\
& Y(t)=C X(t) .
\end{aligned}
$$

Then, the eigenvalues for the system with STATCOM but without any STATCOM controller can be computed and are listed in the first column of Table II. Note that the STATCOM outputs $e_{d}$, and $e_{q}$ remains constant in this case. It is observed from the first column of Table II that the STATCOM mode (characterized by the pair of eigenvalues $-85 \pm j 377$ ) has less damping than the others and the eigenvalues for this mode should be shifted leftward to more desirable locations by a STATCOM controller.

Based on the consideration of enough phase margin, good damping, and good response, the set of controller gains $K 1=$ $15, K 2=15, K 3=10, K 4=50, K 5=-1.23$, and $K 6=-60$ have been determined for the current regulator, the steady-state modulation-index regulator, and the ac voltage controller under the full-load condition with the load switch SW in Fig. 5 closed. It is discovered that the STATCOM controller with the set of controller gains gives satisfactory dynamic voltage responses with the pair of eigenvalues for the STATCOM mode moved to new locations at -2070 and -420 . The eigenvalues of the closed-loop system with the designed STATCOM controller are summarized in the second column of Table II. It is observed from these eigenvalues that good damping effects can be expected.

\section{POWER-Circuit Design}

The system Thevenin-equivalent impedance $Z_{t h}=$ $R_{t h}+j X_{t h}$ in Fig. 2 is very small compared with the STATCOM output filter impedance $Z_{f}=R_{f}+j X_{f}$ and the STATCOM output filter resistance $R_{f}$ is also very small. As a result, the STATCOM output filter can be designed based on the assumptions that the PCC voltage $v_{p c c}$ is harmonic free and the STATCOM output filter resistance is ignored $\left(R_{f}=0\right)$. Thus, the fundamental voltage equation for Fig. 2 can be written as

$$
E_{a n 1}=V_{p c c a}+j I_{a 1} X_{f} .
$$

When the STATCOM is operated at the rated capacitive compensation condition, the STATCOM output harmonic voltage level is the highest. In this case, $E_{a n 1}$ is in phase with $V_{p c c a}$ 
and $\left|E_{a n 1}\right|>\left|V_{p c c a}\right|$. The STATCOM output capacitive current is obtained as follows:

$$
\left|I_{a 1}\right|=\frac{\left|E_{a n 1}\right|-\left|V_{p c c a}\right|}{X_{f}} .
$$

And the total harmonic distortion of the STATCOM output current can be rewritten as follows:

$$
\begin{aligned}
\operatorname{THD}_{\mathrm{i}} & =\frac{1}{\left|I_{a 1}\right|}\left\{\sum_{k=1}^{\infty}\left|I_{a k}\right|^{2}-\left|I_{a 1}\right|^{2}\right\}^{(1 / 2)} \\
& =\frac{1}{\left|I_{a 1}\right|}\left\{\sum_{k=2}^{\infty}\left|I_{a k}\right|^{2}\right\}^{(1 / 2)} \\
& =\frac{1}{\left|I_{a 1}\right|}\left\{\sum_{k=2}^{\infty} \frac{\left|E_{a n k}\right|^{2}}{k X_{f}}\right\}^{(1 / 2)} \\
& =\frac{1}{\left|I_{a 1}\right| X_{f}}\left\{\sum_{k=2}^{\infty} \frac{\left|E_{a n k}\right|^{2}}{k}\right\}^{(1 / 2)} .
\end{aligned}
$$

From (17)

$$
\begin{aligned}
\sum_{k=2}^{\infty} \frac{\left|E_{a n k}\right|^{2}}{k}= & V_{d c}^{2} \\
& \cdot \sum_{m=1}^{m=\infty} \sum_{n= \pm 1}^{n= \pm \infty}\left[\frac{\left(\frac{2 \cdot J_{n}(m M I \pi)}{3 m \pi} \sin \left(\frac{1}{3} n \pi\right)\right)}{(m p+n)}\right]^{2} \\
= & V_{d c}^{2} \cdot f^{2}(M I)
\end{aligned}
$$

where

$$
f(M I)=\sqrt{\sum_{m=1}^{m=\infty} \sum_{n= \pm 1}^{n=\infty}\left[\frac{\frac{2 \cdot J_{n}(m M I \pi)}{3 m \pi} \sin \left(\frac{1}{3} n \pi\right)}{(m p+n)}\right]^{2}} .
$$

After (26) is substituted into (25), the THD of the STATCOM current can be obtained as follows:

$$
\mathrm{THD}_{i}=\frac{1}{\left|I_{a 1}\right| X_{f}} V_{d c} \cdot f(M I) .
$$

After combining (16), (24), and (27), we have

$$
\begin{aligned}
\operatorname{THD}_{i} \cdot\left|I_{a 1}\right| \cdot X_{f} & =V_{d c} \cdot f(M I) \\
\left|I_{a 1}\right| \cdot X_{f} & =\frac{1}{2 \sqrt{2}} M I \cdot V_{d c}-\left|V_{p c c a}\right| .
\end{aligned}
$$

The total current harmonic distortion must be less than $5 \%$ in order to meet the IEEE 519 standard. By solving (28) and (29), the STATCOM output filter reactance can be obtained as follows:

$$
X_{f}=\frac{\left|V_{p c c a}\right| \cdot f(M I)}{\frac{1}{2 \sqrt{2}} M I \cdot \text { THDi } \cdot\left|I_{a 1}\right|-\left|I_{a 1}\right| \cdot f(M I)} .
$$

In this work, $M I$ is equal to 1 and THDi is set as 0.05 when the rated current is chosen as $7.07 \mathrm{~A}(\mathrm{rms})$. Thus, the STATCOM output filter reactance is about $10 \mathrm{mH}$ from (30).
After the STATCOM output filter reactance has been determined, the required steady-state maximum voltage of the dc capacitor can be chosen by substituting (30) into (29). The resultant dc capacitor voltage is as follows:

$$
\mathrm{Vdc}=\frac{2 \sqrt{2}\left(\left|I_{a 1}\right| \cdot X_{f}+V_{p c c a}\right)}{M I} .
$$

Since the dc voltage changes from one level to another during the reversal of the VAR demand, the dc capacitor has a significant effect on the dynamic response when such a dc voltage change occurs. As a result, the capacity of the dc capacitor must be design based on the speed of response during the transient period as well as the dc capacitor voltage ripple in steady-state operation. Generally, a low dc capacitance value results in a fast dynamic response but with high voltage ripples. In contrast, a high dc capacitance value results in a slow dynamic response but with low ripples [5]. In the present work, a dc capacitor of $2200 \mu \mathrm{F}$ has been chosen.

\section{SimUlation AND EXPERIMENTAL Results}

To examine the effectiveness of the proposed analytical approach to the analysis of the line to neutral harmonic voltage and the proposed STATCOM controller with the steadystate modulation-index regulator and transient modulationindex controller, the system in Fig. 5 was simulated using Matlab/Simulink. In addition, a prototype STATCOM for the simple power distribution system in Fig. 5 has been set up in the laboratory. The simulation and experimental results of the proposed STATCOM controller at steady state are illustrated in Fig. 6. Figs. 7 and 8 show the harmonic spectra of the STATCOM output voltage and current in Fig. 6 from the analytical harmonic analysis method in (16) and (17), computer simulations and experiments. Note that the system parameters used in the simulations were the same as those used in the experiments as described in Table I. Both steady-state performance and dynamic responses were investigated. The main purpose for the simulations and the experiments is to show that the proposed analytical approach to the analysis of line to neutral harmonic voltage can perfectly describe the behavior of the STATCOM harmonics, and the proposed STATCOM controller can generate lower harmonic voltages and currents than the STATCOM controller with fixed $V d c^{*}$ and variable $M I$ at steady state.

\section{A. Steady-State Harmonic Performance}

The steady-state response curves for the STATCOM with the proposed STATCOM control scheme and with the STATCOM control scheme with fixed $V d c^{*}$ and variable modulation index $M I$ are compared in Fig. 6. In the simulations and experiments, the STATCOM was operated at the inductive $\operatorname{VAR}\left(i_{q}^{*}=5 \mathrm{~A}\right)$ compensation condition. As shown by the curves in Fig. 6, the experimental results are very close to the simulation results.

It is also noted from Fig. 6(c) and (d) that the dc capacitor voltage was fixed at a high level of $250 \mathrm{~V}$ in the STATCOM controller with fixed $V d c^{*}$ and variable $M I$. The modulation index 


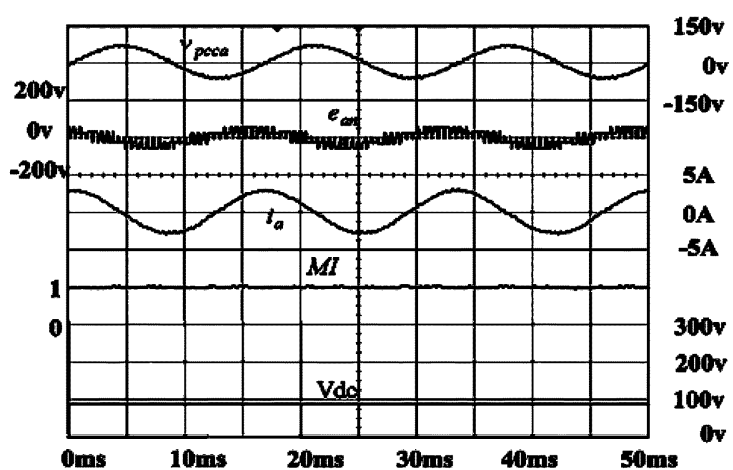

(a)
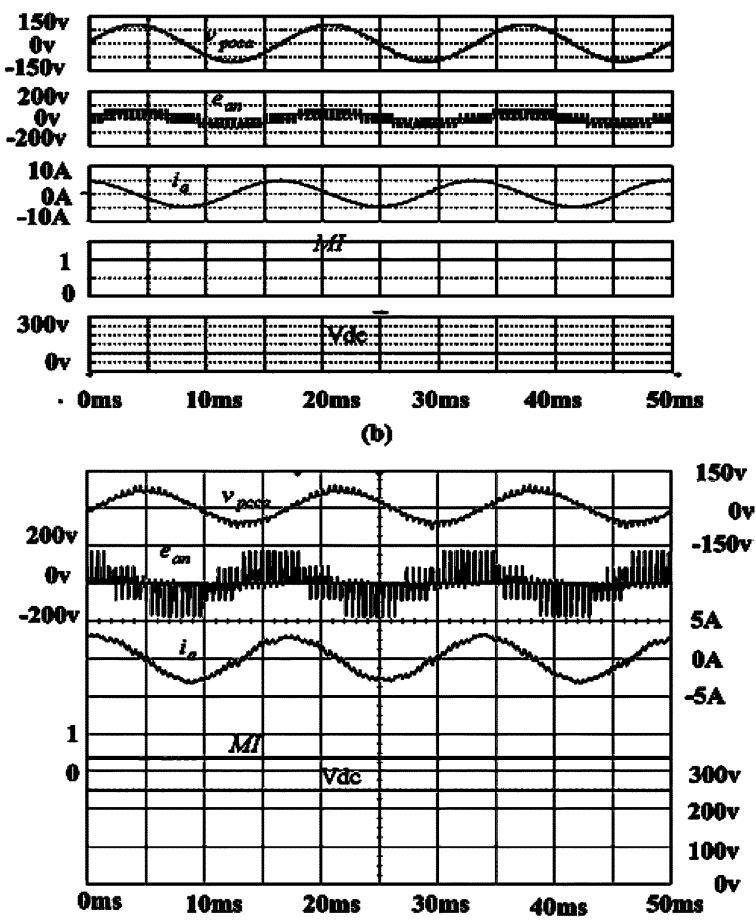

(c)

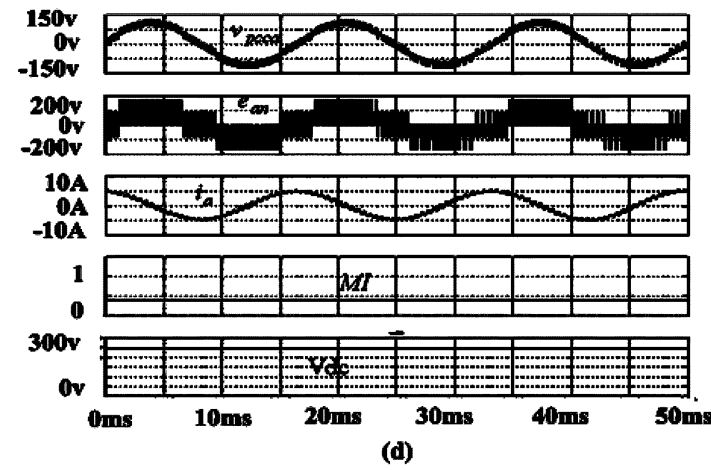

Fig. 6. Steady-state results under the inductive VAR compensation condition. (a) Experimental results using the proposed STATCOM controller (fixed $M I^{*}$ ). (b) Simulation results using the proposed STATCOM controller (fixed $M I^{*}$ ). (c) Experimental results using the STATCOM controller with fixed $V d c^{*}$ and variable $M I$. (d) Simulation results using the STATCOM controller with fixed $V d c^{*}$ and variable $M I$. $\left(v_{p c c a}\right.$ : PCC phase A voltage, $e_{a n}$ : STATCOM phase A output line to neutral voltage, $i_{a}$ : STATCOM phase A output current, $M I$ : modulation index, Vdc: dc capacitor voltage).

was as low as 0.4 for inductive-VAR compensation in Fig. 6(d). This is as expected since a lower modulation index was needed for a lower STATCOM output voltage in the inductive-VAR
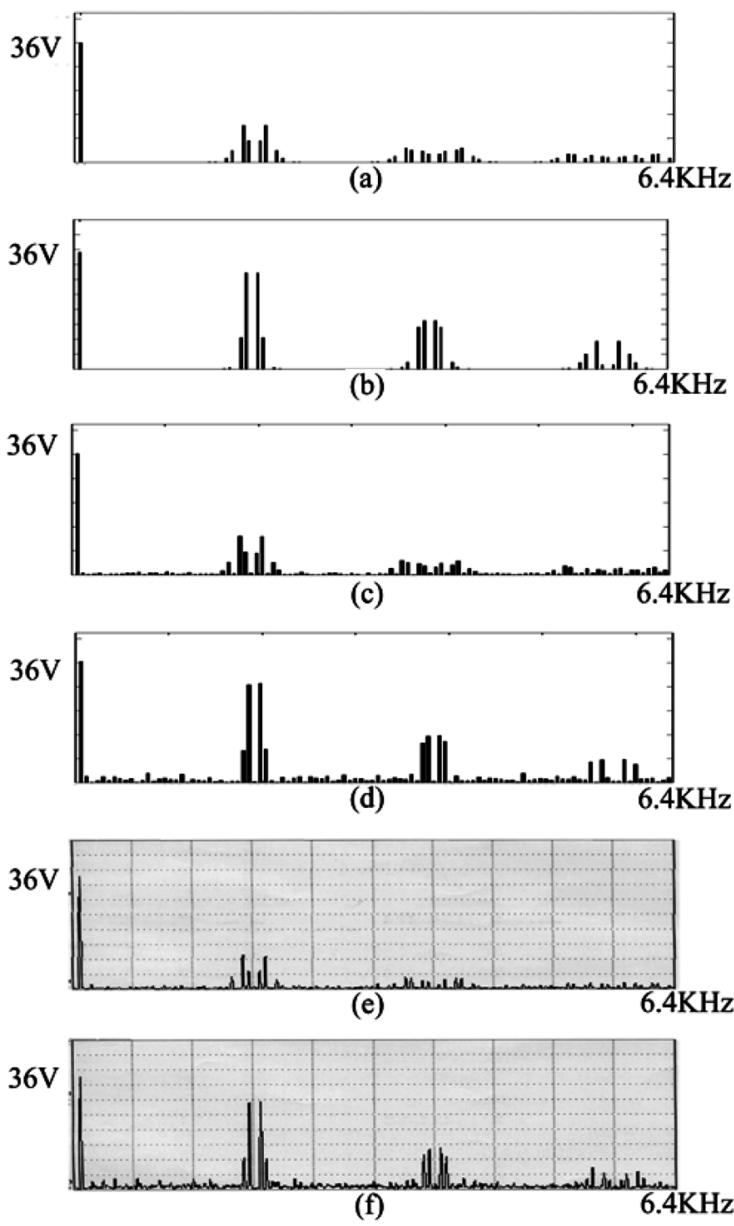

Fig. 7. Voltage harmonic spectra $e_{a n}$. (a) The proposed STATCOM controller (fixed $M I^{*}$ ) by the analytical approach to harmonic analysis. (b) With the STATCOM controller with fixed $V d c^{*}$ and variable $M I$ by the analytical approach to harmonic analysis. (c) With the proposed STATCOM controller (fixed $M I^{*}$ ) by computer simulations. (d) With the STATCOM controller with fixed $V d c^{*}$ and variable $M I$ by computer simulations. (e) With the proposed STATCOM controller (fixed $M I^{*}$ ) by experiments. (f) With the STATCOM controller with fixed $V d c^{*}$ and variable $M I$ by experiments.

compensation case as $V d c^{*}$ was fixed in the STATCOM controller with fixed $V d c^{*}$ and variable $M I$. The low value of the modulation index may cause high harmonic contents as shown in Figs. 7 and 8. On the other hand, the modulation index in the proposed controller remained constant at unity and Vdc was kept at a lower level of $103 \mathrm{~V}$ when the STATCOM was operated under inductive-VAR compensation condition and required a lower output voltage.

By comparing the harmonic spectra in Figs. 7 and 8, obtained by the analytical approach, simulations, and experiments, it is concluded that the results from the analytical approach match closely with the actual spectra from simulations and experiments. It is also noted from Figs. 7 and 8 that the harmonic contents for the proposed STATCOM controller are much lower than those for the STATCOM controller with fixed $V d c^{*}$ and variable $M I$. An observation of the results in Figs. 7 and 8 also reveals that there are some small differences among the harmonic spectra obtained from the analytical approach, computer simulations, and experiments. This is due to the fact that only finite terms have been employed in the summation of 

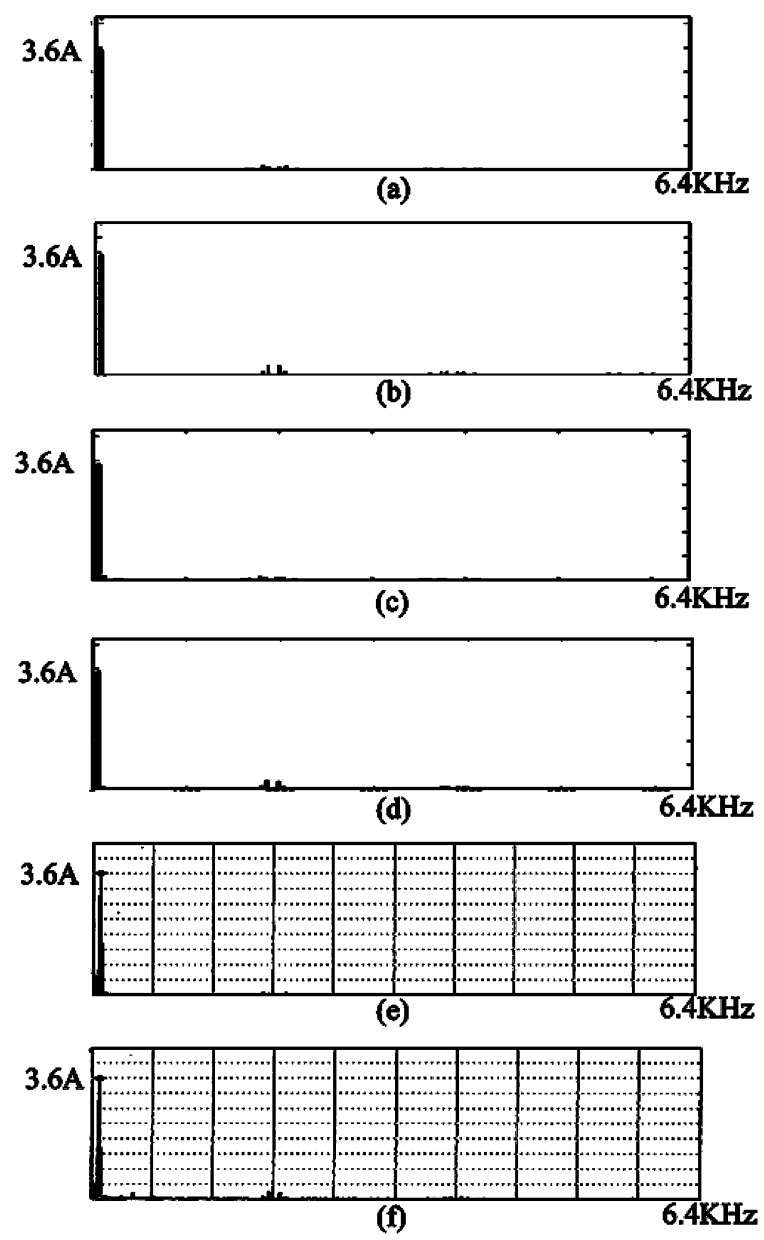

Fig. 8. Current harmonic spectra, $i_{a}$. (a) With the proposed STATCOM controller (fixed $M I^{*}$ ) by the analytical approach to harmonic analysis. (b) With the STATCOM controller with fixed $V d c^{*}$ and variable $M I$ by the analytical approach to harmonic analysis. (c) With the proposed STATCOM controller (fixed $M I^{*}$ ) by computer simulations. (d) With the STATCOM controller with fixed $V d c^{*}$ and variable $M I$ by computer simulations. (e) With the proposed STATCOM controller (fixed $M I^{*}$ ) by experiments. (f) With the STATCOM controller with fixed $V d c^{*}$ and variable $M I$ by experiments.

the Bessel functions in (10). In addition, dead-time effects in the switching elements have not been modeled in the analytical model. Random noises in the experiments may also have little contribution to the differences.

To compare the steady-state performance of the proposed STATCOM control method with fixed $M I^{*}$ and the STATCOM control method with fixed $V d c^{*}$ and variable $M I$, the total harmonic distortion for inverter output voltage (THDv) and inverter output current (THDi) as defined in (18) and (19) are depicted in Fig. 9. It is observed from Fig. 9 that the proposed STATCOM control scheme generates lower THDv and THDi than the STATCOM control scheme with fixed $V d c^{*}$ and variable $M I$ over the entire operational range. The reduction of THDv by the proposed STATCOM controller is more significant when the STATCOM is operated under the inductive-load VAR compensation condition (for example, $\mathrm{Vdc}=103 \mathrm{~V}$ and $M I=1.0$ for the proposed STATCOM controller and $\mathrm{Vdc}=250 \mathrm{~V}, M I=0.4$ for the STATCOM controller with fixed $V d c^{*}$ and variable $M I$ while $i_{q}^{*}=5 \mathrm{~A}$, as shown in Fig. 9(a). It is also observed from Fig. 9(b) that the THDi of

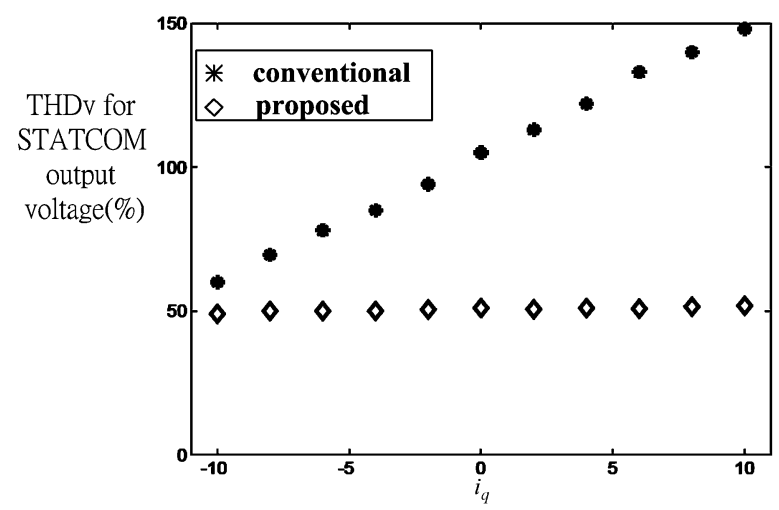

(a)

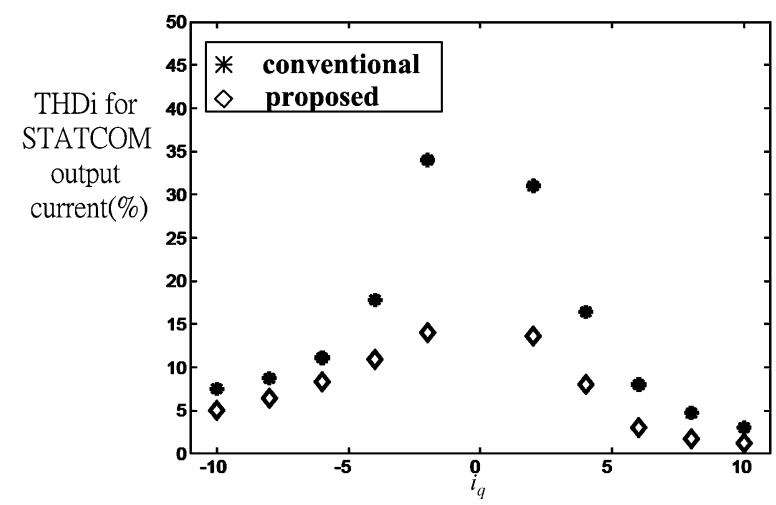

(b)

Fig. 9. Comparison of the THDs from steady-state experiments using the proposed STATCOM controller (fixed $M I^{*}$ ) and the STATCOM controller with fixed $V d c^{*}$ and variable $M I$. (a) STATCOM output phase voltage THDv. (b) STATCOM output current THDi.

the output current from the proposed STATCOM controller is less than that from the STATCOM controller with fixed $V d c^{*}$ and variable $M I$. Note that THDi is undefined when the output reactive fundamental current is close to zero as shown in (19).

To make the STATCOM effective under both capacitance and inductive VAR compensation conditions, the dc capacitor voltage reference $V d c^{*}$ must be maintained at a sufficiently high level. Keeping the dc voltage constant simplifies the voltage control scheme, but increases the switching stress. The high stress is more significant when the STATCOM is operated under inductive reactive power compensation situations since the low modulation index causes narrow pulses from the PWM comparing circuit. The high stress problem can be relieved by using the proposed STATCOM control scheme where the dc voltage reference changes with the reactive power demand and the possibility of narrow switching pulses resulting from low modulation index is reduced. Since the modulation index can be fixed at unity which gives minimal inverter output voltage harmonics in steady state under all possible reactive power demands, the switching pattern for the proposed STATCOM control scheme is composed of wider pulses and the resulting switching stresses are lower.

\section{B. Dynamic Responses}

It has been demonstrated in Fig. 9 that the proposed STATCOM controller with fixed $M I^{*}$ gives better harmonic 


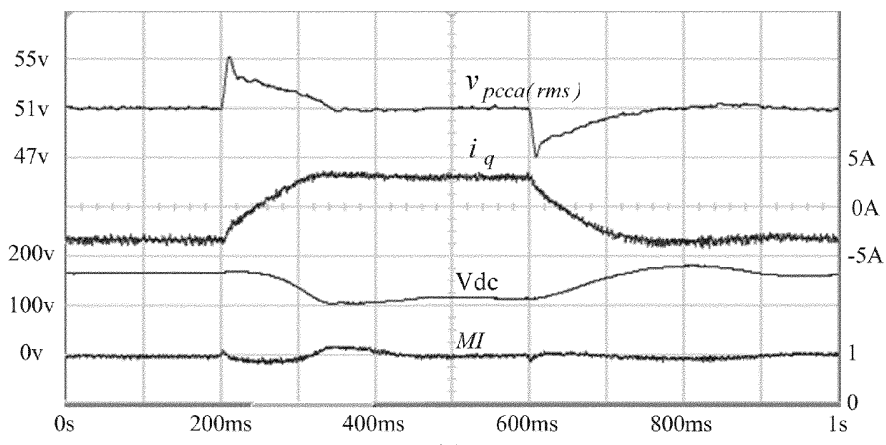

(a)

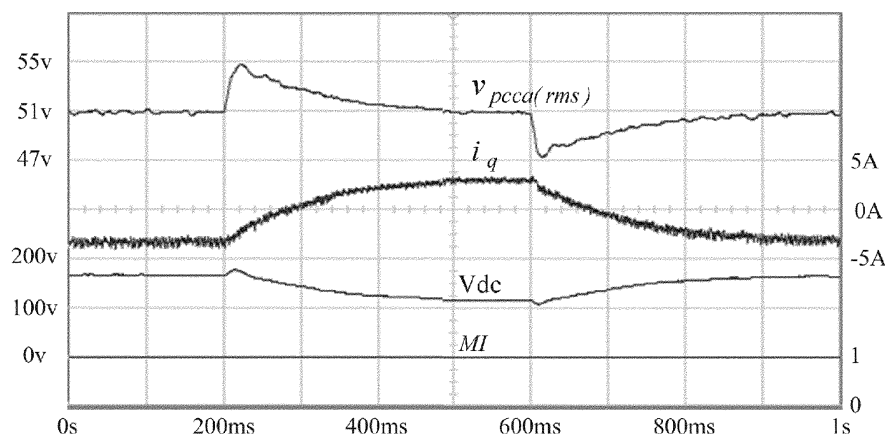

(b)

Fig. 10. Dynamic responses from experiments for load changes. (a) Using the proposed STATCOM controller (fixed $M I^{*}$ ). (b) Using the conventional "alpha only" controller (fixed $M I$ ) (the switchable load impedance $R_{L s w}+j \omega L_{L s w}$ is switched off at $t=200 \mathrm{~ms}$ and on at $600 \mathrm{~ms})\left(v_{\text {pcca }(r m s)}\right.$ : the root-meansquare value of the PCC bus voltage $i_{q}$ : STATCOM output reactive current, Vdc: dc capacitor voltage $M I$ : modulation index).

performance than the STATCOM controller with fixed $V d c^{*}$ and variable $M I$ at steady state. To compare the dynamic performance of the proposed STATCOM controller and the conventional "alpha only" controller, both simulations and experiments were conducted for the system subjected to step load changes. Since the dynamic response curves from simulations were similar to those from experiments, only the experimental results are given in Fig. 10. As shown in Fig. 5, the switchable load impedance $R_{L s w}+j \omega L_{L s w}$ was switched off at $t=200 \mathrm{~ms}$ and switched on at $t=600 \mathrm{~ms}$. It is observed from Fig. 10(a) that the ac bus voltage $V_{p c c a(\mathrm{rms})}$ from the proposed STATCOM controller settled to the reference value of Vrms ${ }^{*}=51 \mathrm{~V}$ in about $130 \mathrm{~ms}$ with an overshoot of $4 \mathrm{~V}$ when the load impedance was switched off at $t=200 \mathrm{~ms}$. In addition, both the reactive current $i_{q}$ and dc capacitor voltage Vdc settled to new levels in about $130 \mathrm{~ms}$. It is also observed from Fig. 10(b) that the ac bus voltage Vrms from the conventional "alpha only" controller settled to the reference value of Vrms $^{*}=51 \mathrm{~V}$ in about $180 \mathrm{~ms}$ with an overshoot of $4 \mathrm{~V}$ when the load impedance was switched off at $t=200 \mathrm{~ms}$.

It is noted from Fig. 10(a) that in response to step load changes, the modulation index MI from the proposed STATCOM controller slightly deviated from the steady-state value immediately following the disturbance, but soon settled to the steady-state value of unity. On the other hand, the modulation index $M I$ from the conventional "alpha only" controller was always fixed at unity during the transient periods of step load change, as shown in Fig. 10(b). With the adjustment of modulation index by the proposed STATCOM controller during the transient period, the STATCOM output voltage can be modulated in a very efficient manner.

\section{CONCLUSION}

An analytical approach based on Bessel functions of the first kind has been presented in the analysis of the harmonics generated by a STATCOM. By comparing the harmonic spectra obtained from the proposed analytical approach and those from simulations and experiments, it has been found that the proposed analytical approach gives harmonic spectra which are very close to those from simulations and experiments.

A novel STATCOM controller, which comprises an ac voltage controller, a current regulator, a steady-state modulation-index regulator, and a transient modulation-index controller has been proposed in this work. Through the fast adjustment of the modulation index during the transient period, the ac bus voltage can be regulated in a very efficient manner since the STATCOM reactive power output can be modulated rapidly. On the other hand, the steady-state harmonics generated by the STATCOM can be kept minimal as the modulation index is held constant at the reference value ( $M I^{*}=1$ in this work) at steady state by the steady-state modulation-index regulator.

By comparing the harmonic spectra for the proposed STATCOM controller and those for the STATCOM controller with fixed $V d c^{*}$ and variable $M I$, it has been concluded that the proposed STATCOM controller generates lower harmonic contents than the STATCOM controller with fixed $V d c^{*}$ and variable $M I$. This is as expected since the modulation index for the STATCOM controller with fixed $V d c^{*}$ and variable $M I$ is not fixed at unity.

\section{REFERENCES}

[1] N. G. Hingorani and L. Gyugyi, Understanding FACTS. New York: IEEE Press, 2000.

[2] C. Schauder, E. Stacey, M. Lund, L. Gyugyi, L. Kovalsky, A. Keri, A. Mehraban, and A. Edris, "AEP UPFC project: Installation, commissioning and operation of the \pm 160 MVA STATCOM (Phase I), IEEE Trans. Power Del., vol. 13, no. 4, pp. 1530-1535, Oct. 1998.

[3] G. F. Reed, J. E. Greaf, T. Matsumoto, Y. Yonehata, M. Takeda, T. Aritsuka, Y. Hamasaki, F. Ojima, A. P. Sidell, R. E. Chervus, and C. K. Nebecker, "Application of a 5 MVA, $4.16 \mathrm{kV}$ D-STATCOM system for voltage flicker compensation at Seattle iron and metals," in Proc. IEEE Power Eng. Soc. Summer Meeting, 2000, pp. $1605-1611$.

[4] C. Schauder and H. Mehta, "Vector analysis and control of advanced static VAR compensators," Proc. Inst. Elect. Eng. C, vol. 140, pp. 299-306, Jul. 1993.

[5] L. Moran, P. D. Ziogas, and G. Joos, "A solid-state high-performance reactive-power compensator," IEEE Trans. Ind. Appl., vol. 29, no. 5, pp. 969-978, Sep./Oct. 1993.

[6] P. W. Lehn and M. R. Iravani, "Experimental evaluation of STATCOM closed loop dynamics," IEEE Trans. Power Del., vol. 13, no. 4, pp. 1378-1384, Oct. 1998.

[7] G. Ledwich and A. Ghosh, "A flexible DSTATCOM operating in voltage or current control mode," Proc. Inst. Elect. Eng., Gen. Transm. Distrib., vol. 149, pp. 215-224, Mar. 2002.

[8] G. Escobar, A. M. Stankovic, and P. Mattavelli, "An adaptive controller in stationary reference frame for D-STATCOM in unbalanced operation," IEEE Trans. Ind. Electron., vol. 51, no. 2, pp. 401-409, Apr. 2004. 
[9] C. Schauder, M. Gernhardt, E. Stancey, T. Lemak, L. Gyugyi, T. W. Cease, and A. Edris, "Operation of \pm 100 MVR STATCON," IEEE Trans. Power Del., vol. 17, no. 4, pp. 1805-1811, Oct. 2002.

[10] K. K. Sen, "STATCOM-STATic synchronous COMpensator: Theory, modeling, and applications," in Proc. IEEE Power Eng. Soc. Winter Meeting, 1999, pp. 1177-1183.

[11] C. K. Sao, P. W. Lehn, M. R. Iravani, and J. A. Martinez, "A benchmark system for digital time-domain simulation of a pulse-width-modulated D-STATCOM," IEEE Trans. Power Del., vol. 17, no. 4, pp. 1113-1120, Oct. 2002.

[12] P. W. Lehn, "Exact modeling of the voltage source converter," IEEE Trans. Power Del., vol. 17, no. 1, pp. 217-222, Jan. 2002.

[13] M. Mohaddes, A. M. Gole, and S. Elez, "Steady state frequency response of STATCOM," IEEE Trans. Power Del., vol. 16, no. 1, pp. 18-23, Jan. 2001

[14] A. R. Wood and C. M. Osauskas, "A linear frequency-domain model of a STATCOM," IEEE Trans. Power Del., vol. 19, no. 3, pp. 1410-1418, Jul. 2004.

[15] J. Hamman and F. S. van der Merwe, "Voltage harmonics generated by voltage-fed inverters using PWM natural sampling," IEEE Trans. Power Electron., vol. 3, no. 3, pp. 297-302, Jul. 1988.

[16] H. S. Black, Modulation Theory. New York: Van Nostrand, 1953.

[17] A. R. Bergen and V. Vittal, Power System Analysis, 2nd ed. Englewood Cliffs, NJ: Prentice-Hall, 2000.

[18] N. Mohan, T. M. Undeland, and W. P. Robbins, Power Electronics: Converter, Applications, and Design. New York: Wiley, 1994.

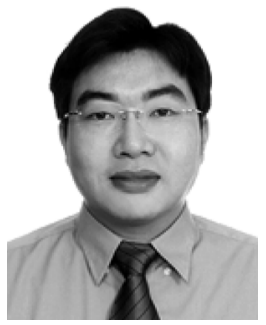

Ben-Sheng Chen received the B.S. degree from National Chiao Tung University, Hsinchu, Taiwan, R.O.C, in 1998, and the M.S.E.E. degree from National Taiwan University, Taipei, in 2000, where he is currently pursuing the Ph.D. degree.

His interests include power electronics, power quality, modern control, and power system analysis.

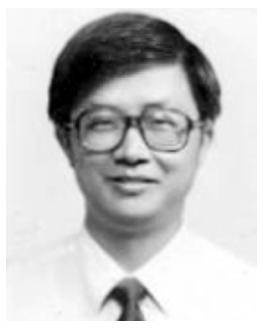

Yuan-Yih Hsu (S'82-M'82-SM'89) was born in Taiwan, R.O.C., on June 19, 1955. He received the B.S., M.S., and Ph.D. degrees in electrical engineering, from National Taiwan University (NTU), Taipei, in 1977, 1980, and 1983, respectively.

Currently, he is a Professor with NTU, where he has been since 1977. His research interests include reactive power compensation and the application of power electronics to power systems.

Dr. Hsu was elected as one of the Ten Outstanding Young Engineers by the Chinese Institute of Engineers in 1989. He received Distinguished Research Awards from the National Science Council in 1986-1995. 